\section{A perilous cause for cardiovocal syndrome}

\section{A PERILOUS CAUSE FOR CARDIOVOCAL SYNDROME}

A 74-year-old man presented with a 2-month history of hoarseness of voice and dyspnoea. He had been on treatment for hypertension and was a chronic smoker. Initial evaluation by an otorhinolaryngologist identified left vocal cord palsy (figure 1A). The chest X-ray appeared normal. For evaluation of coronary artery disease he was referred to the cardiology department. Two-dimensional echocardiography revealed moderate left ventricular dysfunction and dilatation of the ascending aorta. The coronary angiogram showed normal coronary arteries. An aortogram performed with the pigtail catheter in the ascending aorta revealed the presence of a large saccular aneurysm in the aortic arch, opposite to the left subclavian artery ostium, which was protruding inferolaterally (figure $1 \mathrm{~B}$ ). Multidetector CT aortogram showed a $6 \mathrm{~cm} \times 5 \mathrm{~cm}$ saccular aneurysm on the inferolateral border of the aortic arch bulging towards the anatomical site of the ligamentum arteriosum (figure 2). He underwent successful endovascular repair with only slight improvement in voice quality.

Cardiovocal syndrome or Ortner's syndrome is the development of laryngeal nerve palsy due to cardiovascular causes. Though originally described and commonly attributed to an enlarged left atrium in severe mitral stenosis, several other aetiologies have been identified recently. Aortic arch aneurysm though once considered a rare aetiology of Ortner's syndrome; is increasingly being reported. ${ }^{1}{ }^{2}$ A possible association of cardiovocal syndrome with impending rupture has been suggested. ${ }^{3}$ Early identification and definitive management should be offered to prevent perilous consequences.

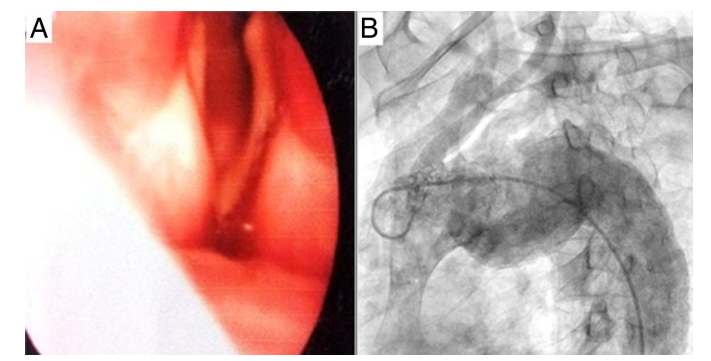

Figure 1 (A) The left vocal cord is appreciated as immobile compared to the right. (B) All 3 branches going upwards from the arch can be seen. Opposite to the left subclavian branch the aneurysm is noted.

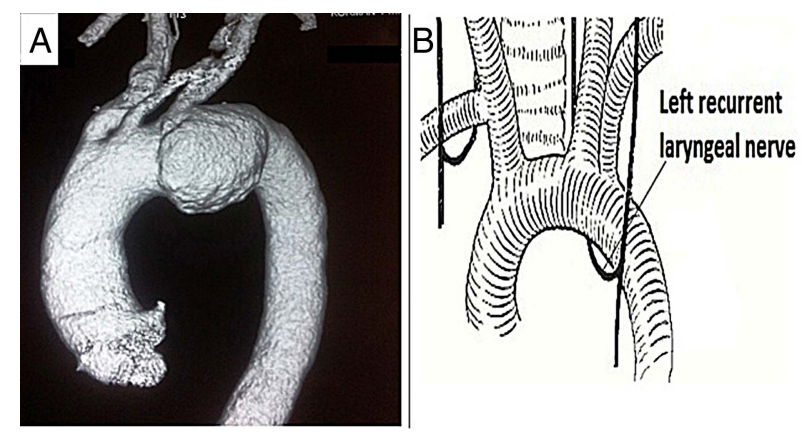

Figure 2 (A) MDCT aortogram showing a $6 \mathrm{~cm} \times 5 \mathrm{~cm}$ saccular aneurysm from the inferolateral wall of the aortic arch, flush with the origin of the left subclavian artery. The aneurysm is seen to bulge inferiorly towards the origin of ligamentum arteriosum. (B) Schematic representation of the course of the left recurrent laryngeal nerve and the mechanism of cardiovocal syndrome. The nerve hooks around the aortic arch directly opposite to the ostium of the left subclavian artery, corresponding to the anatomical site of the ligamentum arteriosum.

\section{Sandeep Mohanan, C G Sajeev, P Kader Muneer, M N Krishnan}

Department of Cardiology, Calicut Government Medical College, Calicut, Kerala, India

Correspondence to Dr Sandeep Mohanan, 'Deepthi', Kavu stop, Chevayoor PO, Calicut, Kerala 673017, India; stg222@gmail.com

\section{Collaborators Prof M N Krishnan}

Contributors The corresponding author has been involved during the entire course of evaluation, care and management of the patient. CGS and PKM had supervised the evaluation and care of the patient and have significantly contributed to making necessary corrections in the paper. MNK has immensely contributed to deciding the treatment plan and further care of the patient.

Competing interests None.

Patient consent Obtained.

Provenance and peer review Not commissioned; internally peer reviewed.

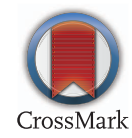

To cite Mohanan S, Sajeev CG, Kader Muneer P, et al. Heart Asia 2014;6:68. doi:10.1136/heartasia-2014-010528

Heart Asia 2014;6:68. doi:10.1136/heartasia-2014-010528

\section{REFERENCES}

1 Annema JT, Brahim JJ, Rabe KF. A rare cause of Ortner's syndrome (cardiovocal hoarseness). Thorax 2004;59:636.

2 Eccles SR, Banks J, Kumar P. Ascending aortic aneurysm causing hoarse voice: a variant of Ortner's syndrome. BMJ Case Rep. Published online: 10 Oct 2012. doi: 10.1136/bcr-2012-007111.

3 Ohki M. Thoracic saccular aortic aneurysm presenting with recurrent laryngeal nerve palsy prior to aneurysm rupture: a Prodrome of Thoracic Aneurysm Rupture? Case Rep Otolaryngol 2012;2012:367873. 